\title{
A Study of Discourse in Relation to Language Learning in English Classes Co-Taught by Native English-Speaking Teachers and Local Teachers in Taiwan
}

\author{
Wen-Hsing Luo ${ }^{1}$ \\ ${ }^{1}$ Department of English Instruction, National Hsinchu University of Education, Taiwan \\ Correspondence: Wen-Hsing Luo, Department of English Instruction, National Hsinchu University of Education, \\ 521 Nanda Rd., Hsinchu City, 30014, Taiwan. Tel: 886-3-521-3132 ext.6722. E-mail: wluo@mail.nhcue.edu.tw
}

Received: April 6, 2013 Accepted: May 5, 2013 Online Published: June 3, 2013

doi:10.5539/elt.v6n7p96 URL: http://dx.doi.org/10.5539/elt.v6n7p96

\begin{abstract}
This study attempts to explore the nature and the potential of various discourse structures and linguistic functions that may facilitate students' learning in English classes co-taught by a native English-speaking teacher (NEST) and a local English teacher in Taiwanese elementary schools. Considering the nature of the study, the author employed a case-study approach to investigate the classroom discourse. In the study, data were analyzed based on a theoretical framework combining discourse analysis schemes, systemic functional theory of language, sociocultural theory of mind and activity theory. The study reveals that repetition drills were commonly used in the classrooms in spite of the difference in the learners' levels, and the Initiating-Responding model was the dominant feature of the classroom discourse structure. The target language, i.e., English, was used by the teachers for demanding information or action, while by the students it was used for repeating and imitating. In light of the findings, the author makes suggestions on co-taught English classes of this kind, for instance, the necessity of creating interactional context for language use, encouraging individual responses from students, and using alternative discourse strategies.
\end{abstract}

Keywords: co-teaching, discourse analysis, elementary schools, native English-speaking teacher

\section{Introduction}

This study aims to describe the features of discourse, i.e., classroom talk, in English classes co-taught by a native English-speaking teacher (NEST) and a local English teacher in Taiwanese elementary schools and to explore the aspects of classroom discourse that may contribute to language acquisition. Mercer (1997) asserted that language is the principal means of communication between the teacher and students in the classroom, through which their thoughts are presented. He stated that discourse is "the representation of thought in language" and "a social mode of thinking" (p. 13). Wells (1999) also suggested that in the community of the classroom, discourse is a means whereby verbal information is valued for the achievement of learning purposes. In the locus of the English classroom, language use or discourse between the teacher and students as well as among students makes up an integral part of students' language learning. Cazden (1988) proposed that classroom talk fulfills three purposes: instructional, managerial and procedural. To facilitate student learning, teachers have to utilize classroom discourse for scaffolding and reconceptualization. Teachers need to assist their students by providing support in a complex learning environment and to induct them into "new ways of thinking about, reconceptualizing or recontextualizing" what is being discussed (Cazden 2001, p. 71). In comparison, Valsiner (1997) viewed classroom discourse from a co-constructivist developmental perspective. Namely, classroom discourse is considered as a process of co-construction which enables teachers and students to create new forms of semiotic mediation and action. In line with this view, Wells (1999) suggested, in order to understand the role of classroom discourse, researchers should attend to the contribution it makes to the classroom activities, the structures of participation, and the functions that discourse performs in mediating the goals of these activities.

In view of the previous research, it is possible, through analyzing the discourse of classroom interaction, to bring to light the relation among discourse structures, language functions and learning in language classrooms. The practice of co-teaching by a NEST and a local English teacher in elementary schools is a direct result of the implementation of the NEST Program (i.e., including NESTs in the school systems) in Taiwan (Author, 2007, 
2010). Using a case-study approach, the author examines the discourse of interaction between the teachers, i.e., a NEST and a local English teacher, as well as that among the teachers and students in an elementary-school English classroom in Taiwan. Additionally, this study aims to gain insights into the type of discourse which may best enable English learning in the classroom. Based on a theoretical framework combining discourse analysis schemes (Sinclair \& Coulthard, 1975, 1992; Wells, 1999), systemic functional theory of language (Halliday, 1984), sociocultural theory of mind (Vygotsky, 1978) and activity theory (Leontév, 1981), the author seeks answers to the following questions:

1) What is the nature of discourse in English classes co-taught by NESTs and local teachers in a Taiwanese elementary school in terms of its structures and language functions?

2) How may discourse as such lead to students' production of the target language items in the English classroom?

\section{Research on Classroom Discourse}

Several studies on the discourse of classroom interaction have been published. For instance, Marton and Tsui (2004) reported studies on classroom discourse in relation to learning of different school subjects in the context of Hong Kong. Pontefract and Hardman (2005) investigated the role of classroom discourse in students' learning of English in elementary schools in Kenya. They found that the discourse pattern of asking students to complete a sentence through a direct repetition of the teacher's verbalization was prevalent in English classes. The Kenyan teachers of English mostly asked factual-narrow questions - which required students only to name objects, spell words or apply a grammatical rule - and elicited choral responses. A similar study conducted by Ackers and Hardman (2001) in Kenyan primary schools showed that teacher-led recitation accounted for approximately $67 \%$ of the teaching and learning activities in English classes. The discourse of classroom interaction was dominated by recitation mode, where the teacher initiates the topics, asks questions, and rarely interacts with the students except to evaluate their responses (Ackers \& Hardman, 2001). The findings of the above studies were echoed in a comparative study by Jan and Hardman (2007) of elementary English classes in Kenya and Nigeria. This study indicated that teachers' initiations were closed, which means they mainly asked students to recall information, and teachers' feedback was largely an evaluation of students' responses.

By comparison, Cullen (2002) examined the role that teachers' follow-up moves play in the English language classroom in Tanzania. He identified two pedagogical roles of follow-up moves: an evaluative and a discoursal role. According to Cullen (2002), the function of the evaluative role is "to provide feedback to individual students about their performance" and its focus is "on the form of the learner's response" (p. 119). Differing from the evaluative role, the discoursal role of the follow-up move is to pick out students' responses "in order to sustain and develop a dialogue between the teacher and the class" and its emphasis is "on content rather than form" (Cullen 2002, p. 120). This study showed that in follow-up moves, teachers made use of four specific strategies: reformulation of a student's contribution, elaboration of a student's response, comment on a student's response and repetition of individual student's contribution. Cullen (2002) characterized the general quality of teachers' follow-up moves as responsiveness, i.e., teachers "listening and responding meaningfully and with genuine interest to the content of what the student is saying" (p. 125).

Lin (2006) looked into classroom interaction between NESTs and students in a Taiwanese junior high school and found that the NESTs utilized three kinds of speech acts, i.e., informative, directive and elicitation acts, to elicit students' output of the target language. The interaction between the NESTs and students in the classroom was in the triadic mode: teacher initiation (I), student response (R), and teacher follow-up (F). Lin (2006) suggested that while the descriptive system proposed by Sinclair and Coulthard could well serve the purpose of coding classroom discourse, further research needs to include content of classroom interaction in data analysis so as to better identify the effects of classroom interaction on student learning. Differing from Lin's study, Shin and Kellogg (2007) looked into teacher talk of a novice NEST comparing that of a local English teacher in an elementary setting in Korea. They found that the NEST's language was simpler with few new words but more grammatical errors. Although it was found that the students used less Korean with the NEST, they also used the target language less.

The above studies investigated the role of classroom discourse in students' learning of English. Through understanding the discourse patterns of classroom interaction, teachers are able to adjust their discourse strategies in a lesson and to facilitate student learning in the classroom (Walsh, 2006a). In order to help teachers achieve a detailed understanding of classroom communication, Walsh (2006a, 2006b) proposed a descriptive framework, self-evaluation of teacher talk (SETT), for analyzing classroom interaction. In this framework, the term mode (cf. Halliday \& Hasan, 1989) is used to define a second-language (L2) classroom micro-context 
which has specific pedagogical goals and interactional features determined mainly by 'a teacher's use of language' (Walsh, 2006b, p. 63). Four distinctive modes are identified (Walsh, 2006a, 2006b): (1) managerial mode, in which the focus is on the management of learning, e.g., setting up a task, summarizing and providing feedback; (2) materials mode, whose pedagogical goals center on materials being used, e.g., eliciting learner response concerning a specific piece of material; (3) skills and systems mode, in which pedagogical goals are to provide learners with practice in relation to a language system or sub-skill; and (4) classroom context mode, whose purpose is to enable learners to talk about their feelings, emotions, experience and attitudes. Walsh (2006b) emphasized that the aim of SETT is to provide a system which facilitates "the description of interactional features, especially of teacher language" in the L2 classroom context and to contribute to the knowledge on "the relationship between language use and second language acquisition" (p. 63).

Previous studies of classroom discourse mainly investigated the interaction in the classroom of one teacher with many students; very few have been conducted in classrooms where two teachers are present (e.g., Creese, 2006). Research on discourse in English classes co-taught by a NEST and a local English teacher is scant. In order to close the gap in this line of research, the present study aims to look into the language use in English classes co-taught by two teachers and how it relates to students' learning in a Taiwanese elementary school. To better investigate the discourse in the English co-teaching classroom, it is necessary to develop a comprehensive coding system, which is employed to closely examine, categorize and code the discourse of classroom interaction. In this study, data were analyzed in terms of discourse structures based on a framework conflating models developed by Sinclair and Coulthard and Wells, into which is incorporated the systemic functional theory of Halliday and his colleagues in order to bring to light the language functions of these discourse structures. In addition, sociocultural theory of mind and activity theory are included in the analysis to provide explanation of how classroom interaction among the teachers and students affects learning per se. In the following sections, the basis of this theoretical framework is described in light of how it relates to the data analyzed in this study.

\section{Theoretical Framework for Discourse Analysis}

\subsection{Linguistic Structures of Discourse}

In their discourse analysis of the English used by teachers and students, Sinclair and Coulthard $(1975,1992)$ proposed a descriptive system in the hope that researchers could use the system as a coding manual in further work analyzing classroom discourse. The system is hierarchical and consists of five ranks, from the lowest to the highest unit of classroom discourse: act, move, exchange, transaction, and lesson. Their research indicated that a typical exchange in the classroom in terms of moves consists of "an initiation by the teacher, followed by a response from the pupil, followed by feedback to the pupil's response from the teacher" (Sinclair \& Coulthard, 1975, p. 21).

Following the system of discourse analysis by Sinclair and Coulthard $(1975,1992)$, Wells (1999) developed a sequential organization of discourse. In Wells' model, a sequence is the unit "of greatest functional significance" (p. 237), which consists of a single nuclear exchange and any exchanges that are bound to it. A nuclear exchange, as the name suggests, can stand alone and contribute new content to the discourse, while bound exchanges may also be present in association with the nuclear exchange. There are three types of bound exchanges: dependent, embedded, and preparatory exchange. Generally, an exchange consists of an initiating move (I), a response move (R), and a follow-up move (F) (Sinclair \& Coulthard, 1975, 1992; Wells, 1999). The structure of a sequence typically begins with the initiating move of the nuclear exchange, and is completed by at least one other participant that "appropriately meets the expectations set up by the initiating move" (Wells 1999, p. 240).

In the present study, structures of classroom discourse are examined and categorized employing the conflation of these two coding systems discussed above. Each instance of spoken discourse is organized within a ranked structure of lesson, sequence, exchange and move. A classroom lesson is composed of opening, instructional, and closing sequences, and each sequence consists of a nuclear exchange with optional preparatory, dependent, and embedded exchanges. A nuclear exchange is a triadic model of interaction involving moves (i.e., the most basic unit of the classroom discourse) of initiating, responding, and follow-up. The argument for constructing this hierarchical scheme is to ensure that units of each level are identifiable and grounded rather than inferred abstractly from the data (Mehan, 1979).

\subsection{Language Functions}

According to Sinclair and Coulthard (1975), three major language functions or contextual types can be identified: statement, question, and command, which are realized in declarative, interrogative, and imperative forms, respectively. In everyday language use, however, the one-to-one correspondence between these functions and forms is much more flexible. While functions of language can be thought of as the way people use their 
language(s) to do different things, it is asserted by Halliday and Hasan (1989) that function needs to be interpreted not only as the use of language but as a fundamental principle of language, and "the organization of every natural language is to be explained in terms of a functional theory" (p. 17). Accordingly, they proposed that language uses vary depending on different contexts of a situation. Three features of the context need to be taken into account: field ("what is happening"), tenor ("who is taking part"), and mode ("what part the language is playing") (p. 12). For example, in the context of a co-teaching English classroom, features of field, tenor and mode can be characterized as follows:

Field: Students learning English (e.g., learning grammar points) in classes co-taught by a NEST and a local English teacher

Tenor: Interaction between teachers and students (e.g., a bid-nomination exchange between the teachers and students in a question-and-answer session)

Mode: Spoken language, spontaneous speech alternating between monologue and dialogue.

\subsection{Sociocultural Theory of Mind (SCT) and Learning in Classrooms}

In addition to the structures and language functions of the classroom discourse, this study also examines the relationship between classroom discourse and learning through the lens of sociocultural theory of mind. From a sociocultural perspective, learning in classrooms is a discursive, socio-historical process (Mercer, 1997), and the classroom discourse process is considered to be a co-construction between the teacher and students (Valsiner, 1997). Two concepts related to sociocultural theory concerning discourse and learning in the classroom are stressed in this study: the ZPD and scaffolding. According to Vygotsky (1978), the notion of the ZPD, the zone of proximal development, provides an alternate perspective on the role of imitation in learning. Using imitation, learners are able to complete more tasks in a collective activity or under the guidance of more capable others than when they work alone. Vygotsky suggested that a learner can imitate when the imitation is within his/her developmental zone, i.e., the ZPD, but imitation can only benefit learning when it approaches the ZPD. Vygotsky (1978) believed that "learning which is oriented toward developmental levels that have already been reached is ineffective" for a learner's overall development, and "good learning is that which is in advance of development" and aims "for a new stage of the developmental process" (p. 89).

Learning is also aided by a process called scaffolding. This is defined as a process that enables a novice "to solve a problem, carry out a task or achieve a goal which would be beyond his/her unassisted efforts" (Wood, Bruner \& Ross, 1976, p. 90). Similarly, described by Maybin, Mercer and Stierer (1992), scaffolding is helpful in "enable[ing] a learner to accomplish a task which they would not have been quite able to manage on their own" and "is intended to bring the learner closer to a state of competence which will enable them eventually to complete such a task on their own" (p. 188). The optimal outcome of scaffolding is that the learner can self-regulate and complete the task independently at a later time. In their discussion of foreign language learning, Aljaafreh and Lantolf (1994) suggested that "different learners have different ZPDs for the same target language form" (p. 473) and feedback from more knowledgeable others is considered a form of scaffolded help, with which the learners are able to extend their current knowledge to higher levels of competence.

\subsection{Activity Theory and Learning}

As an additional theoretical framework, activity theory is also applied in the current study's analysis of discourse and learning. Historically, activity theory has three origins: classical German philosophy (from Kant to Hegel), the writing of Marx and Engels, and the Soviet Russian cultural-historical psychology of Vygotsky, Leontév and Luria (Engeström, 1999). Following Vygotsky's idea of socio-culturally mediated activity, Leontév formulated the Theory of Activity (Lantolf \& Appel, 1994; Wertsch, 1985). Wertsch (1985) stated that an activity is "a socio-cultural interpretation or creation that is imposed on the context by the participants" (p. 203). In other words, an activity is set in a socially constructed context "grounded in a set of assumptions about the appropriate roles, goals, and means to be used by the participants in that setting" (p. 212). Accordingly, instructional or formal educational activity is regarded as one type of activity (Lantolf \& Appel, 1994; Wertsch, 1985). Activities vary according to different features, but the main feature that differentiates one activity from another is its object, which gives an activity a specific direction (Leontév, 1981). Leontév (1981) stated that human activity exists "in the form of an action or a chain of actions" (p. 61) and activities are translated into reality through actions. Following in this line, Wertsch (1985) proposed that the appropriate unit of analysis in Vygotsky's theoretical framework is tool-mediated, goal-directed action. Within the framework of activity theory, therefore, the discourse analysis of co-teaching in an English classroom will focus on how classroom talk is used as a mediation tool to accomplish the object of schooling activity, i.e., students' learning of English. 


\section{The Study}

Considering the nature of the questions being looked into in this study, the author employed a case-study approach to investigate the classroom discourse. Two English classes co-taught by a NEST and a Taiwanese teacher of English (TTE) in an elementary school were included in the study. One of the classes was a sixth grade class and the other one was a fourth grade class. The number of students in both classes was 32 . The sixth grade class was taught by Richard (a NEST) and Lin, and the fourth grade class by Richard and Bea (the names are pseudonyms). Richard is a NEST from the U.S. and had taught English in elementary schools in Taiwan for three years at the time of the research. Both Lin and Bea are TTEs. Lin had taught English with NESTs in elementary schools for eight years and Bea for three years. One unit in each of these two classes was observed by the author. After the unit, the author had an interview with the teachers, respectively. Each of the interviews lasted one to one and a half hours. The purpose of the interviews is to clarify questions arising from the classroom observations. Each unit in the sixth grade class consisted of three co-teaching lessons, whereas there were two co-teaching lessons per unit in the fourth grade class. Each co-teaching lesson lasted 40 minutes. A total of five co-teaching lessons were observed (i.e., three lessons in the sixth grade class and two lessons in the fourth grade class). All the lessons were videotaped for data collection and analysis. The videotapes of these lessons were transcribed. English translations of Mandarin text were provided when necessary for discourse analysis and were sent to the teachers for accuracy check.

\section{Data Analysis}

In the following section, the author presents episodes of the discourse from these two classes (three episodes from the sixth grade class and three from the fourth grade class). These episodes exemplified the discourse of interaction commonly occurred in the classes being studied. Each of these episodes is presented, followed by an analysis using the research framework introduced above. As data was collected in an English classroom co-taught by a NEST and a TTE, it is inevitable that the corpus of spoken data consists of English and Mandarin texts. Mandarin use is shown in boldface font and translations of Mandarin are provided in italics between parentheses. Teachers' errors in English are not marked (e.g., grammatical errors in TTE's utterances, "Let's see teacher Richard is right" and "If teacher Richard is wrong, so we take out one hundred points."), while teachers' actions are shown in brackets.

Episodes A1, A2, and A3 occurred in the sixth grade class in a unit on verb forms of present tense and present progressive tense. Episode A1 took place in Lesson 1 of this unit, while Episode A2 occurred in Lesson 2 and Episode A3 in Lesson 3 of the same unit.

Episode A1

[L: Lin R: Richard S1: Student one S2: Student two Ss: Students]

1. R: Now, have a look at the vocabulary on page forty-nine. Oh, what's the difference? What is it?

2. Ss: Reading a book.

3. R: What's the difference?

4. S1: Yige shi 'now' (One is 'now').

5. R: This is 'now'?

6. L: No. What is the difference?

7. R: Look! [Draw a circle around -ing]

8. S2: I-N-G

\section{L: Right, I-N-G}

\section{R: I-N-G}

\section{Ss: I-N-G}

Episode A1 consists of instructional sequences and presents the progression of negotiating meaning among the teachers and students. In Turn 1, Richard directed the class's attention to the vocabulary on page forty-nine and asked them to detect the difference between verb forms of present tense and present progressive tense. The field of the context is expressed in Turn 1, which indicates the activity orientation of this discourse: noticing the verb ending -ing in the present progressive tense. In this episode, the teachers and students were the tenors and engaged in an activity of noticing the verb ending in the present progressive tense (i.e., the field of the context). Through meaning negotiation (the spoken mode) (from Turns 1 to 9) and with scaffolding from the teacher (in 
Turn 7), the teachers and students mediated the goal of the activity, which was to help the students notice the verb ending in present progressive tense and ultimately attain the knowledge of the particular grammar point.

Episode A2

1. L: Hao (okay), jiou sentence de comparison (for sentence comparison), OK, one is 'everyday', one is 'now', right? 'Everyday' is what you do seven days a week, Monday, Tuesday, Wednesday, right? So when we know 'everyday' you can do is no I-N-G, but 'now', it has I-N-G. Hao, xuoyi women zhidao jintian de jiou meiyou I-N-G, duei bu duei? (Okay, so we know that today doesn't go with I-N-G) Shenme dongxi meiyou I-N-G? (What doesn't go with I-N-G?)

\section{S1: Bushi xianzai (It is not 'now'.)}

3. L: Shi dongzuo meiyou I-N-G, duei bu duei? (Action doesn't go with $I-N-G$, right?) Suoyi women de 'see' meiyou I-N-G (So I-N-G doesn't go with 'see'.), Ranhou women de 'do' ye meiyou I-N-G (Then 'do' doesn't go with $I-N-G$ either), suoyi ni buneng shuo 'What do you doing everyday?' (So you can't say 'What do you doing everyday?') Buxin, shi 'What do you do?' (No. It is 'What do you do?') 'You' goes with 'DO'. Hao, ze women yi qian jiu xue guo le (Okay, we already learned this before.) because it is 'everyday' so it is 'sing a song' and no 'S' here, why? Weishenme bushi 'sings a song'? (Why is it not 'sings a song'?) Why not?

4. S1\&S2: Because it is not 'he' or 'she'.

5. L: Because it is not 'he' or 'she'. It's 'I'. Because we say 'I/you', no 'S', 'he/she', 'S'. Okay. Ni kan I-N-G, hao, na ni dou zhidao yong I-N-G tsai shi zhi xianzai 'now, I-N-G'. Hao, na shiyong I-N-G haiyou yi ge yao ji de jioushi.... (You see, $I-N-G$, you all know that $I-N-G$ means 'now'. Okay, one more thing you need to remember when you use $I-N-G$ is....)

\section{L \& Ss: 'Are'}

7. L: 'You' goes with 'are'. Ze ge 'are', women youge mingzi jiao jiou 'be' dongci. na 'be' dongci you sange, nimen xianzai xue guo de jiao you 'is, am, are'. (This 'are', there is a name for it. It is called 'be' verbs. There are three 'be'verbs you have learned, 'is, am, 'and 'are'.) Na (Then) 'is' goes with 'he' and 'she', and 'are' goes with 'you' and 'I', and 'I', sorry, 'am' goes with 'I'. Na zeli 'you' suoyi women yong 'are', suoyi you I-N-G yiding qianmian yao you.... (Then here it is 'you', so we use 'are'. So before $I-N-G$, there must be....)

8. S1: 'Are'

9. L: ‘Are'. Suoyi (So) you cannot say ‘What do you doing?’ No.

10. L \& S1: 'What are you doing?'

11. L: Hao (Okay). Same thing, Ji ran shi 'I', suoyi women yao 'goes with am'. (since it is 'I', we need to 'goes with am '). Na ni buneng shuo (Then you can't say) 'I singing a song', no, you have to say 'I'm singing a song' or 'I am singing a song.' Liao bu liaojie. Hao, suoyi zege 'am' hen zhongyao, 'are' hen zhongyao. (Understood? Okay, so this 'am' is important, 'are' is important.) Ok. All right.

12. R: Okay. Let's see what we can do now. I'm going to ask the question. I'm going to say, 'What do you do every day?' Answer?

13. Ss: 'I read a book every day.'

14. R: And then I'm going to say, 'What are you doing?'

15. Ss: 'I'm reading a book.'

16. L: So the keyword you have to listen to is 'every day'. Okay? All right.

The discourse shown in Episode A2 is in the form of a monologue-like lecture. Lin initiated the sequence with a statement (Turn 1), which expresses the field of the context and indicates the activity orientation of this discourse: explaining a grammar point (the usage of verb-ing in the present progressive tense). Lin asked a question ("Shenme dongxi meiyou I-N-G?"), and one student voluntarily responded to it (Turn 2). In Turn 3, Lin did not evaluate the student's response; rather, she provided the answer herself and continued explaining the usage of -ing. At the end of Turn 3, Lin initiated a new sequence by asking the whole class another question ("Weishenme bushi 'sings a song'? Why not?"), and students responded to the question (Turn 4). Lin took up the follow-up move in the first part of Turn 5 by repeating the students' answer ("because it is not he or she"), which functions as explanation but also evaluation (acceptance) of the students' contribution to the discourse. After repeating the answer, Lin explained further the use of '-ing' with 'are' and started another sequence (from the end of Turn 5 to Turn 16), in which the nuclear exchange specifies the importance of be verbs in the use of -ing. In this episode, 
the teachers and the whole class were engaged in an activity of grammar explanation about the use of -ing and be verbs. Through requesting and providing information, they mediated the goal of the activity, i.e., to help the students understand this particular grammar point. The students could produce the forms of -ing and be verbs as they answered the NEST's questions correctly (in Turns 13 and 15).

Episode A3

1. R: Remember we can find the answer from the question. How will you begin the answer? 'What is she doing?' 'She' and 'is'... the answer is 'She is eating dumplings.'

2. Ss: 'She is eating dumplings.'

3. R: 'Let's go to the library.'

4. Ss: 'Let's go to the library.'

5. R: 'What are we doing?'

6. Ss: 'What are we doing?'

7. R: Well, we said 'What are we doing?' How does the answer begin?

8. Ss: 'We're.'

9. R: 'We're.' Good. 'We're reading.'

10. Ss: 'We're reading.'

In Episode A3, Richard initiated a sequence with a statement, which indicates the field of the context and the activity orientation of this discourse: learning to answer the questions "What are/is you/he/she doing?" In Turn 2, the whole class took up the responding move in unison by repeating the sentence, "She is eating dumplings." The following two exchanges (from Turn 3 to Turn 6) are in an I-R move pattern. In Turn 7 ("Well, we said 'What are we doing?' How does the answer begin?"), Richard gave a hint of the answer (i.e., a form of scaffolded help) to the students. In Turn 8, the class replied with the correct answer ("We're."). In this episode, Richard and the class were engaged in an activity of drilling sentences containing the present progressive tense taught in this unit. Through the spoken mode: sentence drilling and repeating, the teacher and the students mediated the goal of the activity: to help the students gain accuracy in saying sentences in the present progressive tense.

In the next section, episodes from the discourse of interaction in the fourth grade class are presented. Episodes B1, B2 and B3 were from a unit on vocabulary of emotions (such as angry, happy, and sad). Episode B1 was from Lesson 1 of this unit, while both Episodes B2 and B3 were from Lesson 2 of the same unit.

Episode B1

[B: Bea R: Richard Ss: Students]

1. R: Turn to page fifty-one.

2. B: Fifty-one, fifty-one.

3. R: Okay Repeat after me.

4. B: Fifty-one. Unit six, unit six.

5. Ss: Unit six.

6. R: Page fifty-one. Okay. 'Hi, David.'

7. Ss \& B: 'Hi, David.'

8. R: 'Hi, David.'

9. Ss \& B: 'Hi, David.'

10. R: 'Hi, Alan.'

11. Ss \& B: 'Hi, Alan.'

12. R: 'Are you happy?'

13. Ss \& B: 'Are you happy?'

14. R: 'Today?'

15. Ss \& B: 'Today?' 
16. R: 'Yes, I am.'

\section{Ss \& B: 'Yes, I am.'}

In Episode B1, Richard started a nuclear exchange in Turn 1 ("Turn to page fifty-one.”), in which the students were told what to focus on (i.e., page fifty-one). The activity orientation of the discourse is expressed in the nuclear exchange, i.e., repeating the dialogue taught in this unit on the vocabulary of emotions. The second sequence progresses through the rest of this episode (from the second part of Turn 3 to Turn 17). The role of Richard's talk in Turn 1 ("Turn to page fifty-one") and in the second part of Turn 3 ("Repeat after me"), both of which are initiating moves, is to organize and plan the classroom instruction. Bea repeated what Richard said ("Fifty-one, fifty-one" in Turn 2) and provided additional information for the class ("Unit six, unit six" in Turn 4). Bea's talk in Turns 2 and 4, both of which are responding moves, is characterized as supporting the instruction. The rest of the second sequence (from the second half part of Turn 6 "Hi, David." to Turn 17 "Yes, I am.") consists of a series of dependent exchanges of the NEST reading and the students repeating (along with the TTE). In this episode, the teachers and the whole class were engaged in an activity of repetition of the dialogue being taught. Namely, the NEST read the dialogue and the students (with the TTE) repeated. Through repetition, they mediated the goal of the activity, which was to help the students attain accuracy of the dialogue being taught.

Episode B2

1. R: Ok, I can say, 'Are you happy?' Or I can say, 'Are you...?' [Point at the sentence strips on the board]

2. Ss \& B: 'Sad?'

3. R: Or are you...

4. Ss \& B: 'Angry?'

5. R: Okay. Now ready? One, two, three [Point at the sentence strips on the board]

6. Ss: 'Are you sad?'

7. Ss: 'Are you happy?'

8. Ss: 'Are you angry?'

9. R: Cool! Very good. This is a good class.

In Episode B2, a nuclear exchange begins in Turn 1 when Richard pointed at the sentence strips on the board and said "Okay. I can say, 'Are you happy?'....", and it continues as the students and Bea replied in Turn 2. The activity orientation of the discourse is expressed in the nuclear exchange, i.e., practicing question sentence patterns (“Are you angry/happy/sad?") following the NEST's direction, while the dependent exchange (from Turn 3 to Turn 5) specifies the content of the discourse. The second sequence is initiated by Richard in Turn 5 when he pointed at the sentence strips on the board and said "Now, ready. One, two, three." The initiating moves by Richard are not shown in the discourse data as they are indicated by hand pointing at the sentence strips on the board. In this episode, the teachers and the students were engaged in an activity of drills of sentences "Are you angry/happy/sad?" The mode of the discourse is not entirely spoken, but is drill-oriented. The function of the initiating move by the NEST is demanding for action: saying the sentences being pointed at on the board. Through demanding for action, the teachers and the students mediated the goal of the activity: gaining the accuracy of the sentences which contained the vocabulary of emotions taught in this unit.

Episode B3

1. R: If I say, ‘Are you angry?’ Everyone, one, two, three, go.

2. B \& Ss: 'No, I'm not. I'm happy.'

3. R: How about I say, 'Are you sad?'

4. B \& Ss: 'No, I'm not. I'm happy.'

5. R: I say, 'Are you angry?'

6. B \& Ss: 'No, I'm not. I'm happy.'

7. R: Okay. Now, let's put them all here. Teacher Bea, can you find someone to come up here?

8. B: Okay, I'll call Tricky.

In this episode, a nuclear exchange is initiated by Richard in Turn 1 and progresses to Turn 2 when Bea and the class took on the responding move. This nuclear exchange (Turns 1 and 2) indicates the activity orientation of 
the discourse: answering sentences using vocabulary of emotions, such as angry, happy and sad. Turns 3 and 4 make up a dependent exchange (in an I-R move pattern) bound to the nuclear exchange, while Turns 5, 6 and the beginning part of Turn 7 ("Okay.") constitute another dependent exchange (in an I-R-F move pattern) in this sequence. The second sequence begins in Turn 7 ("Now, let's put them all here....") and ends in Turn 8 ("Okay, I'll call Tricky."). This episode shows a series of I-R-(F) exchanges, in which the NEST initiated and the TTE or the students (with the TTE) responded. The mode of the discourse is spoken, drill-oriented, and the language function of the initiating moves by the NEST is a demand for replies (i.e., to have the students answer the questions that contain the vocabulary of emotions taught in the unit). Through the spoken mode: asking and replying, the teachers and the students mediated the activity goal, which was to help the students gain accuracy in using the vocabulary of emotions, such as angry, happy and sad in the sentence patterns being taught.

\section{Discussion of Findings}

In this section, findings are discussed in relation to the research questions of this study: what is the nature of classroom discourse in the co-teaching classroom and how may the discourse as such lead to students' production of the target language?

\subsection{Nature of Classroom Discourse and Students' Production}

\subsubsection{Field of Discourse - Teacher-fronted and Drill Activities}

The study shows that the field of the discourse, i.e., the activity orientation of the discourse, in these two classes was mainly teacher-fronted drills (of grammar or vocabulary). There was no student-regulated learning activity in any form in either class. Yet, incidents in which the students appropriated scaffolding from the teacher and consequently produced the target language (i.e., English) items were observed (as shown in Episodes A1 and A3) The 'motive' underlying the classroom learning activities was drill- rather than education-oriented (Lantolf, 2000). Namely, the students did not use the target language independently when participating in the activities. Rather, they were engaged in repetition and imitation of the target language items taught in the class. Without the opportunity to use the target language, for instance, in dialogic interaction, the students are not able to negotiate their own learning (Swain, 2000).

\subsubsection{Tenor of Discourse - Teachers vs. Whole Class}

The study indicates that the role of tenor in both classes was assumed by the teachers and the students, most of time, as a whole class. Although both teachers took on the role of tenor, the NEST would mostly initiate the discourse of interaction in the classes, while the TTE in the sixth grade class would initiate the discourse when she started a new lesson or explained grammar points (as shown in Episode A2). The fact that the NEST as tenor took on most of the initiating moves in the classroom discourse suggests a lack of collaborative nature of discourse between the NEST and the TTE. Additionally, the finding that the whole class, instead of individual students, assumed the role of tenor (e.g., in teacher-reading and student-repeating sessions) suggests a lack of opportunity in the classroom for the students to develop learner autonomy in English learning.

\subsubsection{Mode of Discourse - Teacher-reading and Student-Repeating}

This study reveals that, the mode of discourse (in the classification by Halliday \& Hasan, 1989) commonly seen in the classes was in spoken form: repetition (e.g., teacher-reading and student-repeating, in which the teachers read the texts or sentences and the students repeat what the teacher said) (as shown in Episodes A3 and B1). Another mode of discourse was monologue by the teacher (e.g., the TTE explained grammar points as shown in Episode A2). In the teacher's monologue, the language plays the role of clarifying and providing information. The study shows that the teachers' use of language in the classes can be characterized as the managerial, materials, and skills and systems modes (in Walsh's classification 2006a, 2006b). No classroom context mode, whose purpose is to enable learners to express themselves, is found in either of these two classes. While this finding is not surprising, as it has been shown in previous studies (e.g., Pontefract \& Hardman, 2005), repetition activities as such do not involve the students in higher mental processes, e.g., thinking and reasoning, and would consequently affect the degree of student achievement in English learning (Soled, 1990).

\subsubsection{Initiating Move - Demanding/Organizing}

Similar to the previous studies (e.g., Ackers \& Hardman, 2001; Jan \& Hardman, 2007), this study shows that the teachers, mostly the NEST, were the initiators of the sequences in the classes and their utterances functioned as a demand for information (e.g., "Somebody tell me what page it is.") or action (e.g., "Turn to page 41."). Another function of the initiating moves in the classroom discourse is: organizing or planning classroom activities, such as organizing what the class would do in the lesson (e.g., "We are going to start a new lesson, which is the last lesson of this semester." and "If I say, 'Are you angry?' Everyone, one, two, three, go.”). The finding indicates 
that opportunities for student-initiated participation in the classroom discourse as well as situations which require students' higher-order thinking were limited (cf. Jan \& Hardman, 2007).

\subsubsection{Responding Move- Repeating/Imitating}

The author finds that the responding moves were undertaken mainly by the students, whose utterances were limited to repetition and imitation of the text or sentences read by the NEST. There were minimal occasions when the students replied to the teachers' questions. For instance, in Episode A1, the NEST asked, "What's the difference?" and one student replied "yige she now (one is now)." The study also finds that choral responses, which place lower cognitive and linguistic demands on the students (cf. Pontefract \& Hardman 2005), were prevalent in the classrooms. It is argued that learning outcomes of activities which engage students only in repetition and imitation might be less favorable than those of activities which require higher mental processes (Soled, 1990), and this type of discourse of classroom interaction does not encourage the students to experiment with the target language (Pontefract \& Hardman, 2005). Additionally, in line with Pontefract and Hardman (2005), the study shows that the word length of student responses was mostly one-word, which indicates that the students "had little opportunity to respond at length to teacher initiations" (p. 97).

\subsubsection{Follow-up Move - Evaluating/Repeating}

Exchanges of the classroom discourse in these two classes mainly progressed in an I-R move pattern. The teachers' follow-up moves were not commonly seen and when they occurred they functioned as evaluation or repetition of students' responses (e.g., as shown in Episode A2). This finding echoes Cullen's study (2002) in that two pedagogical roles of the follow-up moves were identified: evaluative and discoursal. The language use in the follow-up moves as evaluation of students' performance was usually positive feedback (e.g., "Okay" and "Good"), and in the discoursal follow-up moves the language was used for repetition of students' replies. It is argued that teachers' follow-up moves that simply repeat students' responses render limited support of language learning to students. As Cullen (2002) stated, in discoursal follow-up moves support for language learning consists in the teacher's provision of "a rich source of message-oriented target language input as s/he reformulates and elaborates on the students' contributions and derives further initiating moves from them" (p. 122).

The above discussion shows that the discourse of interaction in the classes was mostly led by the NEST in a manner of teacher-reading and student-repeating. Incidents in which the students could produce the target language items were scant, and when they occurred, the students' production was limited to one or two words. The classroom activities were largely teacher-fronted drills and the students did not have opportunity to use the target language independently but simply responded to the teacher in chorus or repeated what the teacher said.

\subsection{Findings beyond Discourse Analysis}

In this section, the author wishes to discuss findings that are beyond the scope of discourse analysis, but are rather intriguing. The study finds that the TTEs took on the responding moves along with the students. For instance, the TTE Bea in the fourth grade class repeated with the students after the NEST (as shown in Episodes B1, B2, and B3). When asked why she did so, Bea remarked that she repeated with the students as a way to help the students pay attention to the lesson and encourage them to repeat after the NEST. As well, Bea took on the responding moves to re-emphasize what the NEST said, e.g., "Fifty-one, fifty-one" and "Fifty-one, unit six, unit six" (as shown in Episode B1) to ensure that the students followed the instruction well. The author finds that Richard asked Bea to call on students, instead of doing so himself, to participate in game activities (as shown in Episode B3). When asked about this incident, Bea replied:

"The foreign teacher asked me to call on students to play the game activities because as a TTE, I think I know better the students' ability and I am able to group students in activities appropriately according to their levels."

Another intriguing finding concerns the use of English and Mandarin Chinese as the medium of instruction. In both of the classes, the use of English outweighed that of Mandarin Chinese. In the fourth grade class, English was the sole medium of instruction, while in the sixth grade class Mandarin Chinese was used as a tool to mediate classroom activities when the TTE explained the grammar points. When asked why English was used as the medium of instruction, Bea remarked:

"I would like to provide an English-only environment for my students. I believe that they can follow the instruction well even if the lessons are taught in English. I will use TPR approach and a lot of repetition to help them understand what the lessons are about."

Lin commented on why Mandarin Chinese was used when she explained grammar points to the students: 
"Some English grammar points are difficult for the students. To help the students understand the grammar points, I will explain to them in their first language. It will help them to grasp the instruction if I teach in Chinese."

The above remarks indicate that the teachers' decision of using students' first language in foreign language instruction is dependent on the levels of difficulty of the content being taught rather than the grade levels of the students.

\section{Suggestions}

With the light shed by the above discussion, the author wishes to make the following suggestions. First, responses other than choral responses should be incorporated in the discourse of classroom interaction. The study shows that students' responses were mostly choral responses, in which English was used by the learners mainly for repetition and imitation. Through imitating and repeating in chorus, students might be able to appropriate the help of others and therefore produce the target language items. However, choral responses require only a low level of cognition on the part of the students and might discourage students' development of the target language (Pontefract \& Hardman, 2005). Furthermore, given the concept that learning takes place more effectively in interactional contexts which are socially and culturally embedded, foreign language learners need to explore different language functions for communication in order to attain a communicative repertoire (McGroarty, 1993). The author suggests the teachers create multiple activity types for language use and acquisition as well as encourage individual responses from the students. Learners need to use the target language in various situations such as communicating information, accomplishing tasks and expressing feelings, so as to grow in language competence.

Next, follow-up moves should be used wisely in an efficacious way for students' language learning. The author finds that follow-up moves by the teachers functioned as evaluating or repeating student responses. In spite of the fact that students' contributions to the classroom discourse are limited due to their level of English ability, it is favorable for the teachers to help the learners move towards "a new stage of the development process" (Vygotsky 1978, p. 89) through alternative discourse strategies. For instance, rather than simply repeating or evaluating students' responses, teachers can incorporate their responses into subsequent questions. The following excerpts from a study by Cullen (2002) can be an example of this process:

$\mathrm{T}$ : Where was the picture taken?

S1: In the airplane.

T: In the airplane. Good, yes. In the airplane.

$\mathrm{T}$ : What do you call this man in the white shirt?

S2: The....

T: Just one word is enough.

S2: Pilot.

T: Pilot. Yes. The pilot.

T: Now what is this other man holding?

S3: A pistol.

T: A pistol. Right.

T: Now what kind of man is he? What do you call such men who have pistols and point them at pilots?

S4: We call a robber.

T: A robber? Yes. A thief you mean? Yes, if this was happening on the ground, it could be a thief, but this man's in a plane.

T: Can you tell me-- what is he telling the pilot? Suppose you are there. What is he telling the pilot?

S5: He is telling him 'Hands up!'

T: Hands up!

(excerpts adapted from Cullen, 2002)

In this process, teachers engage students 'in a probing and extended discussion' in which they chain teacher questions and student responses together so that the classroom discourse takes on "conversation-like quality" and encourages student-initiated ideas and promotes higher-order thinking (Ackers \& Hardman 2001, p. 259). Through this process, teacher feedback is in the form of scaffolding that is needed for learners' development 
beyond their current level. Teacher feedback which functions as scaffolding could encourage negotiation of meaning in the classroom discourse between the teacher and students. As Cullen (2002) stated, teacher's feedback plays a significant role "in clarifying and building on the ideas that the students express in their responses" and consequently "in developing a meaningful dialogue between teacher and class" (p. 126). While I-R-F structure is a traditional pattern of classroom interaction and "fits the transmission of facts and routinized procedures," it does not emphasize "processes and strategies for learning and doing" (Cazden 2001, p. 5). As Cazden (2001) suggested, teachers should promote classroom discourse where students not only take listening responsibilities but are given speaking rights and are encouraged to ask metacognitive questions.

The third suggestion is regarding the use of learners' first language and the target language in the classroom. The study shows that the target language, English, was the medium of instruction in both classes, and the learners' first language, Mandarin Chinese, was used only on the occasions for explaining English grammar in the sixth grade class. This finding reveals the role of learners' first language as a tool to mediate classroom activities, i.e., to help the learners understand grammar instruction, which could be difficult for them without the assistance of the first language. Given that classroom interaction should facilitate processes and strategies for learning (Cazden, 2001), the author suggests that the use of learners' first language and the target language in foreign language instruction be decided according to the difficulty of classroom activities rather than the level of learners. The use of learners' first language should not be completely restricted as the learners, especially the low achievers, need the linguistic assistance of their first language in order to understand the instruction (cf. Antón \& DiCamilla, 1998).

Finally, the author wishes to suggest the necessity of collaboration between the NEST and the TTE, in which co-taught classroom discourse is sustained. The author finds that the discourse of interaction between the NEST and the TTE in the classroom was mostly led by the NEST, i.e., the NEST being the initiator of the sequences, while the TTE repeated with the students after the NEST (as shown in the fourth grade class). The occurrence of discourse between the teachers was observed when they called upon the students to answer questions in game activities. However, no discourse of interaction between the teachers was found in giving lessons/activities together. While this might be an intriguing finding regarding the roles played by the teachers in the co-teaching English classroom, the author argues that classroom discourse of a collaborative nature will benefit student learning of English in the classroom taught by a NEST and a TTE. Studies examining discourse of a collaborative nature in relation to language acquisition in the classroom of this kind are necessary in order to bring to light the role of teacher talk (i.e., NESTs' and local teachers') in student learning of English.

\section{Conclusion}

In conclusion, this study reveals that repetition drill activities were found in both of these two classes, and the I-R model was the feature of the classroom discourse structure. The use of the target language, English, by the teachers was mainly for demanding information or action, while by the students it was for repeating and imitating. The classroom discourse was mostly led by the NEST, and the occurrence of discourse between the NEST and the TTE was not substantially observed in the study. Due to the nature of a case study, the findings of the present study may not be generalized to a different context. It is hoped that this study may inform teachers as well as teacher educators of the characteristics and the potential of classroom talk that may facilitate students' production of English in co-teaching English classrooms of this kind. The author wishes to call for more studies on the discourse of interaction in English classrooms so as to better understand its effect on English learning and optimally to develop pedagogy which is beneficial for student learning.

\section{Acknowledgements}

This study is part of a research project funded by Taiwan's National Science Council.

\section{References}

Ackers, J., \& Hardman, F. (2001). Classroom interaction in Kenyan primary schools. Compare, 31(2), 245-261. http://dx.doi.org/10.1080\%2F03057920120053238

Aljaafreh, A., \& Lantolf, J. P. (1994). Negative feedback as regulation and second language learning in the zone of proximal development. The Modern Language Journal, 78, 465-483. http://dx.doi.org/10.2307\%2F328585

Antón, M., \& DiCamilla, F. J. (1998). Socio-cognitive functions of L1 collaborative interaction in the L2 classroom. The Canadian Modern Language Review, 54, 314-342. http://dx.doi.org/10.3138\%2Fcmlr.54.3.314 
Cazden, C. B. (1988). Classroom discourse: the language of teaching and learning. Portsmouth, NH: Heinemann.

Cazden, C. B. (2001). Classroom discourse: the language of teaching and learning (2nd ed.). Portsmouth, NH: Heinemann.

Creese, A. (2006). Supporting talk? Partnership teachers in classroom interaction. International Journal of Bilingual Education and Bilingualism, 9(4), 433-453. http://dx.doi.org/10.2167\%2Fbeb340.0

Cullen, R. (2002). Supportive teacher talk: The importance of the F-move. ELT Journal, 56(2), 117-127. http://dx.doi.org/10.1093\%2Felt\%2F56.2.117

Engeström, Y. (1999). Activity theory and individual and social transformation. In Y. Engeström, R. Miettinen, \& R-L. Punamäki (Eds.), Perspectives on activity theory (pp. 19-38). Cambridge, UK: Cambridge University Press. http://dx.doi.org/10.1017\%2FCBO9780511812774.003

Halliday, M. A. K. (1973). Explorations in the functions of language. London: Arnold.

Halliday, M. A. K. (1984). Language as code and language as behavior: a systemic-functional interpretation of the nature and ontogenesis of dialogue. In R. P. Fawcett, M. A. K. Halliday, S. M. Lamb, \& A. Makkai (Eds.), The semiotics of culture and language, 1 (pp. 3-35). London: France Printer.

Halliday, M. A. K. (1993). Towards a language-based theory of learning. Linguistics and Education 5, 93-116. http://dx.doi.org/10.1016\%2F0898-5898\%2893\%2990026-7

Halliday, M. A. K. (1994). An introduction to functional grammar (2nd ed.). London: Arnold.

Halliday, M. A. K., \& Hasan, R. (1985). Language, context, and text: Aspects of language in a social-semiotic perspective. Victoria, Australia: Deakin University Press.

Jan, A-K., \& Hardman, F. (2007). The discourse of whole class teaching: a comparative study of Kenyan and Nigerian primary English lessons. Language \& Education: An International Journal, 21(1), 1-15.

Lantolf, J. P. (2000). Introducing sociocultural theory. In J. P. Lantolf (Ed.), Sociocultural theory and second language learning (pp. 1-28). Oxford, UK: Oxford University Press.

Lantolf, J. P., \& Appel, G. (1994). Theoretical framework: An introduction to Vygotskian approaches to second language research. In J. P. Lantolf, \& G. Appel (Eds.), Vygotskian approaches to second language research (pp. 1-32). Norwood, New Jersey: Ablex Publishing Corporation.

Leontév, A. N. (1981). The problem of activity in psychology. In J. V. Wertsch (Ed.), The concept of activity in Soviet psychology (pp. 37-71). Armonk, NY: Sharpe.

Lin, F. (2006). A study of classroom interaction between native English-speaking teachers and Taiwanese junior high school students. Unpublished master's thesis. Tunghai University, Taiwan.

Marton, F., \& Tsui, A. B. M. (2004). Classroom discourse and the space of learning. Mahwah, NJ: Lawrence Erlbaum Associates.

Maybin, J., Mercer, N., \& Stierer, B. (1992). "Scaffolding" learning in the classroom. In K. Norman (Ed.), Thinking voices: The work of the National Oracy Project (pp. 186-195). London: Hodder and Stoughton for the National Curriculum Council.

McGroarty, M. (1993). Cooperative learning and second language acquisition. In D. D. Holt (Ed.), Cooperative Learning: A Response to Linguistic and Cultural Diversity (pp. 19-46). Washington, DC: Center for Applied Linguistics and ERIC Clearing House on Languages and Linguistics.

Mehan, H. (1979). Learning lessons: Social organization in the classroom. Cambridge, MA: Harvard University Press.

Mercer, N. (1997). Socio-cultural perspectives and the study of classroom discourse. In C. Coll, \& D. Edwards (Eds.), Teaching, learning and classroom discourse: Approach to the study of educational discourse (pp. 13-21). Madrid, Spain: Fundación Infancia y Aprendizaje.

Pontefract, C., \& Hardman, F. (2005). The discourse of classroom interaction in Kenyan primary schools. Comparative Education, 41(1), 87-106. http://dx.doi.org/10.1080\%2F03050060500073264

Shin, J., \& Kellogg, D. (2007). The novice, the native, and the nature of language teacher expertise. International Journal of Applied http://dx.doi.org/10.1111\%2Fj.1473-4192.2007.00144.x 
Sinclair, J. McH., \& Coulthard, M. (1975). Towards an analysis of discourse: the English used by teacher and pupils. Oxford: Oxford University Press.

Sinclair, J. McH., \& Coulthard, M. (1992). Towards an analysis of discourse. In M. Coulthard (Ed.), Advance in spoken discourse analysis (pp. 1-34). London: Routledge.

Soled, S. W. (1990). Teaching processes to improve both higher and lower mental process achievement. Teaching and Teacher education, 6, 255-265. http://dx.doi.org/10.1016\%2F0742-051X\%2890\%2990017-Y

Swain, M. (2000). The output hypothesis and beyond: Mediating acquisition through collaborative dialogue. In J. P. Lantolf (Ed.), Sociocultural theory and second language learning (pp. 115-132). Oxford, UK: Oxford University Press.

Valsiner, J. (1997). Bounded indeterminacy in discourse processes. In C. Coll, \& D. Edwards (Eds.), Teaching, learning and classroom discourse: Approach to the study of educational discourse (pp. 23-32). Madrid, Spain: Fundación Infancia y Aprendizaje.

Vygotsky, L. S. (1978). Mind in society: The development of higher psychological processes. Cambridge, MA: Harvard University Press.

Walsh, S. (2006a). Talking the talk of the TESOL classroom. ELT Journal, 60(2), 133-141. http://dx.doi.org/10.1093\%2Felt $\% 2$ Fcci100

Walsh, S. (2006b). Investigating classroom discourse. London: Routledge.

Wells, G. (1999). Dialogic inquiry: Towards a sociocultural practice and theory of education. Cambridge, UK: Cambridge University Press. http://dx.doi.org/10.1017\%2FCBO9780511605895

Wertsch, J. V. (1985). Vygotsky and the social formation of mind. Cambridge, Mass: Harvard University Press.

Wood, D., Bruner, J. S., \& Ross, G. (1976). The role of tutoring in problem solving. Journal of Child Psychology and Psychiatry, 17, 89-100. http://dx.doi.org/10.1111\%2Fj.1469-7610.1976.tb00381.x

\section{Copyrights}

Copyright for this article is retained by the author(s), with first publication rights granted to the journal.

This is an open-access article distributed under the terms and conditions of the Creative Commons Attribution license (http://creativecommons.org/licenses/by/3.0/). 